Research Article

\title{
Investigation on Supersonic Flow Control Using Nanosecond Dielectric Barrier Discharge Plasma Actuators
}

\author{
A. Nazarian Shahrbabaki $(D$, , M. Bazazzadeh $(\mathbb{D}$, and R. Khoshkhoo \\ Faculty of Mechanical Engineering, Malek-Ashtar University of Technology, Iran \\ Correspondence should be addressed to M. Bazazzadeh; bazazzadeh@mut-es.ac.ir
}

Received 25 April 2021; Revised 16 June 2021; Accepted 24 June 2021; Published 15 July 2021

Academic Editor: Jose Carlos Páscoa

Copyright (c) 2021 A. Nazarian Shahrbabaki et al. This is an open access article distributed under the Creative Commons Attribution License, which permits unrestricted use, distribution, and reproduction in any medium, provided the original work is properly cited.

\begin{abstract}
In this paper, the effects of streamwise Nanosecond Dielectric Barrier Discharge (NS-DBD) actuators on Shock Wave/Boundary Layer Interaction (SWBLI) are investigated in a Mach 2.5 supersonic flow. In this regard, the numerical investigation of NSDBD plasma actuator effects on unsteady supersonic flow passing a $14^{\circ}$ shock wave generator is performed using simulation of Navier-Stokes equations for 3D-flow, unsteady, compressible, and $k-\omega$ SST turbulent model. In order to evaluate plasma discharge capabilities, the effects of plasma discharge length on the flow behavior are studied by investigating the flow friction factor, the region of separation bubble formation, velocity, and temperature distribution fields in the SWBLI region. The numerical results showed that plasma discharge increased the temperature of the discharge region and boundary layer temperature in the vicinity of flow separation and consequently reduced the Mach number in the plasma discharge region. Plasma excitation to the separation bubbles shifted the separation region to the upstream around $6 \mathrm{~mm}$, increased SWBLI height, and increased the angle of the separation shock wave. Besides, the investigations on the variations of pressure recovery coefficient illustrated that plasma discharge to the separation bubbles had no impressive effect and decreased pressure recovery coefficient. The numerical results showed that although the NS-DBD plasma actuator was not effective in reducing the separation area in SWBLI, they were capable of shifting the separation shock position upstream. This feature can be used to modify the structure of the shock wave in supersonic intakes in off-design conditions.
\end{abstract}

\section{Introduction}

Shock Wave/Boundary Layer Interaction (SWBLI) is a key phenomenon of fluid dynamics, and its analysis is important in many supersonic and hypersonic applications, especially in various supersonic intakes, airfoils, and other aerodynamic and propulsion parts of vehicles [1]. It can highly affect the performance of a propulsion system. SWBLI generates an adverse pressure gradient at the interaction region with the consequences of flow separation, increased viscous dissipation, increased drag, and increased thickness of boundary layer [2]. Figure 1 shows a schematic of the SWBLI structure in a supersonic flow over a shock generator including incident and separation shocks, reflected shock, sonic line, and separation point [3]. According to the figure, Mach stem, incident shock, and reflected shock intersect in the so-called triple point. The height of the triple point is one of the most important factors in SWBLI strength. The flow separationinduced shock angle is an influential factor of the height of the triple point which increases under the influence of compressive waves. The adverse pressure gradient caused by SWBLI sometimes induces flow separation and separation bubbles, which can lead to a reverse flow in the boundary layer, increase the boundary layer thickness, and decrease aerodynamic drag force and stagnation pressure resulting in significant performance loss of intakes. In addition, it generates nonuniform and oscillating inlet flows and results in unstarting conditions of intake. Therefore, controlling SWBLI with the approach of reducing the length of the separation region ignited strong research interest [4]. 


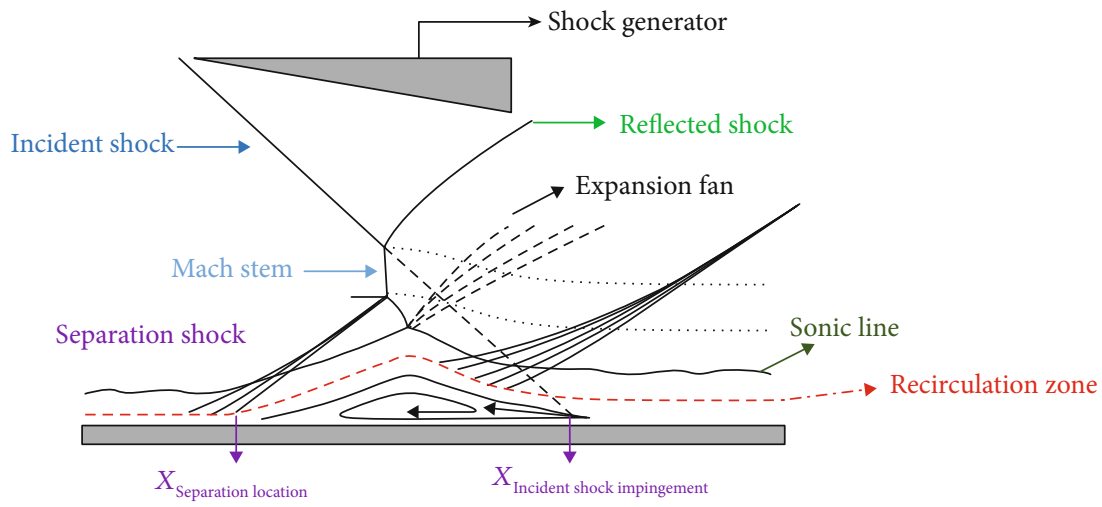

FIgURE 1: A schematic of SWBLI in a supersonic flow passing a shock generator [3].

Flow control strategies are classified by different methods. Flow control strategies are divided into active and passive techniques. Using vortex generators (in the form of microramp or microvane) [5] and placement of grooves/riblets [6] are among the passive strategies. Boundary layer suction/blowing [7], variable geometry systems [8], and plasma actuators [9-12] are among the active strategies. All the methods and devices have their own advantages and disadvantages. Energy deposition using a plasma actuator to the fluid flow is one of the strategies. Plasma actuators, however, have been in the area of focus due to their simple structure, rapid response, lower power consumption, controllability, and lack of moving parts [13].

Alternating Current Dielectric Barrier Discharge (AC-DBD) plasma actuators are one of the frequently used plasma actuators classified within nonthermal electrohydrodynamic actuators [14-18]. They are driven with sinusoidal alternating current and induce ionic wind as a wall jet near the plasma-produced region and thus can add momentum to the boundary layer. AC-DBD plasma actuators have been widely used and shown to be effective for the reduction of flow separation at low-speed flow regimes with low Reynolds numbers [17]. Nanosecond DBDs (NS-DBDs) are another type of plasma actuators [19]. Unlike AC-DBDs, it generates a heated gas layer instead of inducing ionic wind. It has recently attracted the attention of scholars in controlling high-speed flows [20, 21]. Figure 2 shows the schematic of a NS-DBD plasma actuator [22]. According to the figure, NS-DBD generates a high temperature region within few microseconds by applying a pulse-wise potential difference. Nanosecond actuators have a significant thermal impact compared to AC-DBDs [22]. Energy deposition in the form of localized heating is the main mechanism by which the actuators control supersonic flows. They instantaneously increase pressure and generate compressive waves around the heating region through rapid localized heating [23].

NS-DBD plasma actuators, spark jet, and arc plasma are among conventional thermal actuators [24, 25]. NS-DBD has a high-voltage DC input with nanosecond pulses with a specific frequency. High-voltage pulses generate heat and increase the local pressure of flow and, in turn, form cylindrical compressive waves. The variations of the input voltage and frequency of these nanosecond pulses could highly affect

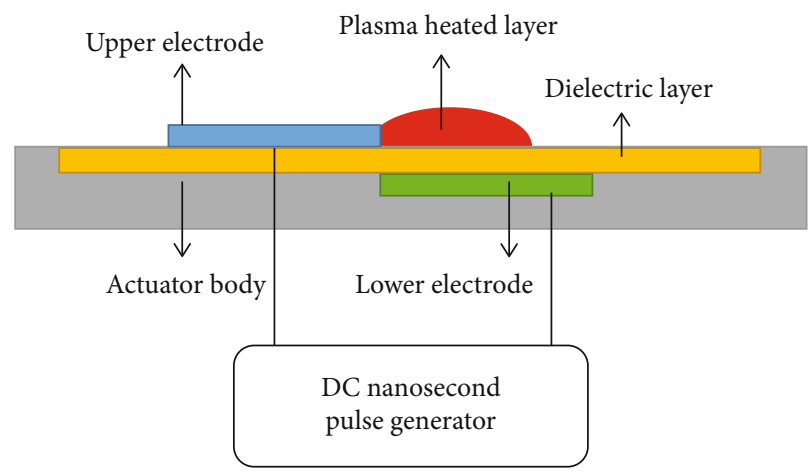

FIgURe 2: A schematic of a NS-DBD actuator.

the heating rate and the intensity of wave penetration to the flow. The specifications of NS-SDBD flow actuation have been numerically and experimentally studied in the literature for different flow regimes.

The effect of NS-DBD actuators on a supersonic flow $(\mathrm{Mach}=2)$ has been investigated in Webb's study [26]. Based on the presented results in [26], by the placement of a plasma actuator in the upstream of flow, a significant amount of energy was transferred to the fluid in the SWBLI region which, in turn, decreased the separation region and shifted reflected shock wave to the upstream by $4 \mathrm{~mm}$. Falempin et al. [27] investigated the effect of weakly ionized plasma on controlling the location of a shock in a supersonic intake with a Mach number ranging from 2 to 3 and in off-design condition. According to their results, plasma actuation with different output powers had a significant effect on shock wave's structure so that a plasma actuator with an optimized output power of $8.1 \mathrm{~kW}$ shifted the location of shock wave to the upstream, decreased the angle of initial shock, and decreased the intensity of the secondary shock.

In addition to the tendency to use NS-DBD plasma actuators in supersonic flow control, array-type plasma actuators have become a research hotspot in SWBLI control during the last decade [28-30]. The array-type excitation consists of arc plasma actuators which are focused on the spot localized heating. Although the input electric field for array-type actuations and NS-DBD plasma actuators is the same as each other, the main control mechanism of both actuators could 


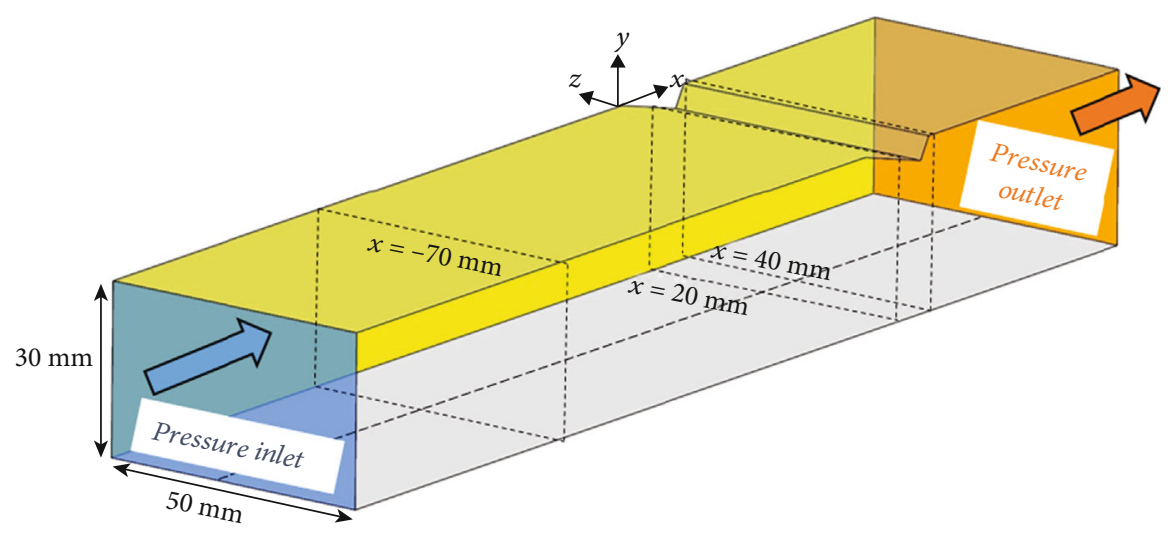

FIgURE 3: Schematic of computational domain and applied boundary conditions.

be different from each other's according to their configurations, direction of excitation, etc. Therefore, they have the same effect on the fluid flow in the same conditions. Besides, the NS-DBDs are easy to build and install on the control body and distribute the temperature on the domain of flow control uniformly.

The NS-SDBD plasma actuator operated in two ways for SWBLI control: first, boundary layer heating and second, vorticity generation near the generated plasma surface. For the first way, the boundary layer heating made the size of the separation bubble increased and consequently the SWBLI stronger. In this condition, the ND-DBD actuator and the generated heating layer over the discharge region may be effective in the movement of separation shock upstream and increasing the shock wave angle. But using the second way is more capable to overcome the boundary layer separation. The main reason is the vortex generation and consequently transferring the momentum from the core flow to the boundary layer. As experimental approaches to observe such a physical process around the plasma region and SWBIL are so complicated, have diagnostic limitations, and are timeconsuming, developing a numerical approach is essential to recognizing the unknowns of SWBLI and shock position control using NS-DBDs and their control mechanisms.

Previous studies in the fields of NS-DBDs almost have been focused on actuator modeling or application of those for the subsonic and supersonic separation control. Therefore, numerical investigation on the direction of plasma discharge (in streamwise type) and investigating its effect on separation length and separation shock position are a novel subject which is focused in the current paper. The novelty of this paper is applying parallel plasma configurations to finding out the main mechanism of NS-DBD effects on supersonic flow and separation region. In this regard, the present study is aimed at evaluating the effect of parallel plasma actuators' discharge and its length/location on SWBLI, specifications of separation bubbles, and position of the separation shock wave by numerical simulations. So, as the first step, the numerical model of the baseline flow (without actuation) is verified using distribution of wall pressure and schlieren image around the SWBLI. At the second step, parallel configuration of NS-DBD with various lengths is applied with the numerical model to explore the effects of
NS-DBD on separation length and shock wave position. In the end, the main control factor of actuators for streamwise NS-DBD is presented.

\section{Governing Equations, Statement of the Problem, and Boundary Conditions}

A Mach 2.5 supersonic flow was simulated, and the effects of NS-DBD actuation on SWBLI were investigated. NavierStokes equations were considered to be the governing equations of the studied flow, and the $k-\omega$ SST model was used for turbulence modeling. The governing equations are as follows, and more details are explained in [22]:

$$
\begin{gathered}
\frac{\partial \rho^{*}}{\partial t^{*}}+\nabla^{*} \cdot\left(\rho^{*} \vec{U}^{*}\right)=0 \\
\frac{\partial \rho^{*} \vec{U}^{*}}{\partial t^{*}}+\nabla^{*} \cdot\left(\rho^{*} \vec{U}^{\bar{*}} \vec{U}^{*}\right)-\frac{1}{\operatorname{Re}} \nabla^{*} \cdot \overline{\bar{\tau}}^{*}=0, \\
\frac{\partial \rho^{*}}{\partial t^{*}}+\nabla^{*} \cdot\left[\left(\rho^{*}+p^{*}\right) \vec{U}^{*}-\frac{1}{\operatorname{Re}}\left(\vec{U}^{*} \cdot \overline{\bar{\tau}}^{*}\right)=Q,\right.
\end{gathered}
$$

where nondimensional quantities are denoted by superscript * and $\vec{U}^{*}=\left\{u^{*}, v^{*}, w^{*}\right\}, \rho^{*}, p^{*}, t^{*}$, and $\overline{\bar{\tau}}^{*}$ represent the velocity vector, density, pressure, time, and shear stress tensor, respectively. The nondimensional quantities are obtained through the following relations:

$$
\rho^{*}=\frac{\rho}{\rho_{\text {ref }}}, U^{*}=\frac{U}{U_{\text {ref }}} p^{*}=\frac{p}{\rho_{\text {ref }} U_{\text {ref }}^{2}}, \mu^{*}=\frac{\mu}{\mu_{\text {ref }}}, T^{*}=\frac{T}{T_{\text {ref }}},
$$

where the subscript (ref) denotes the reference values. $\mu^{*}$ and $T^{*}$ represent the molecular viscosity coefficient and temperature, respectively. Nondimensional parameters Re and $Q$ denote the Reynolds number and deposited energy, respectively. The perfect gas is assumed, and the molecular viscosity coefficient is calculated by Sutherland's law.

A density-based solver was used to solve the governing equations. The equations were discretized by second-order schemes, and for the momentum and energy equation 


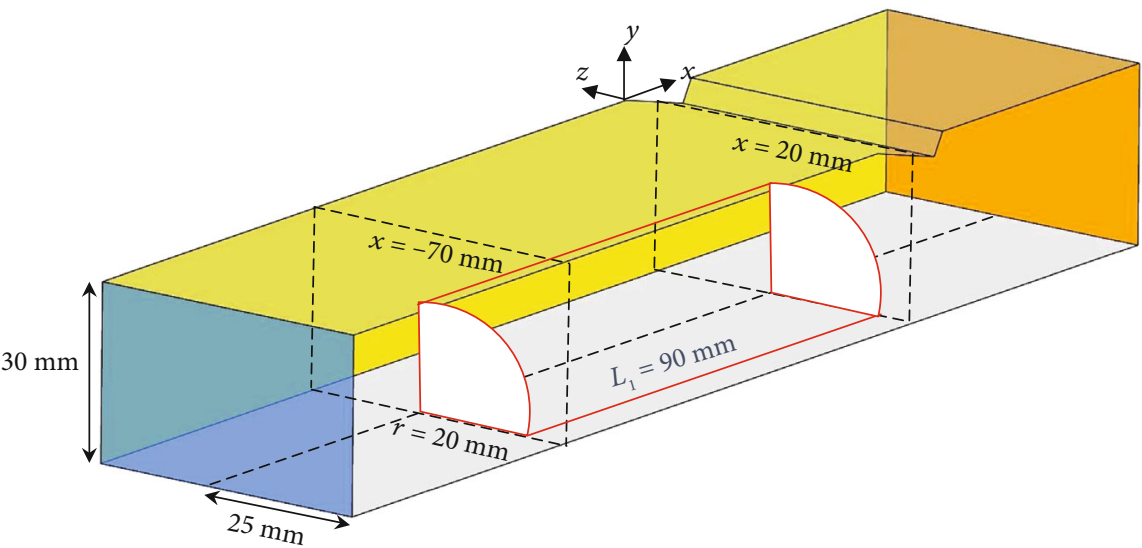

(a) Test case number $1\left(L_{1}\right)$

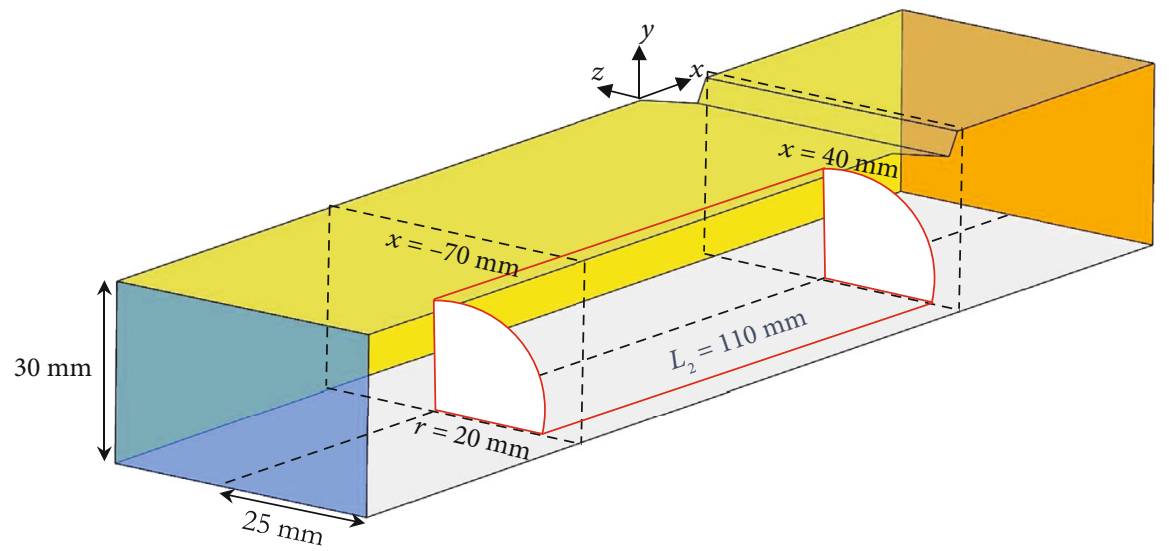

(b) Test case number $2\left(L_{2}\right)$
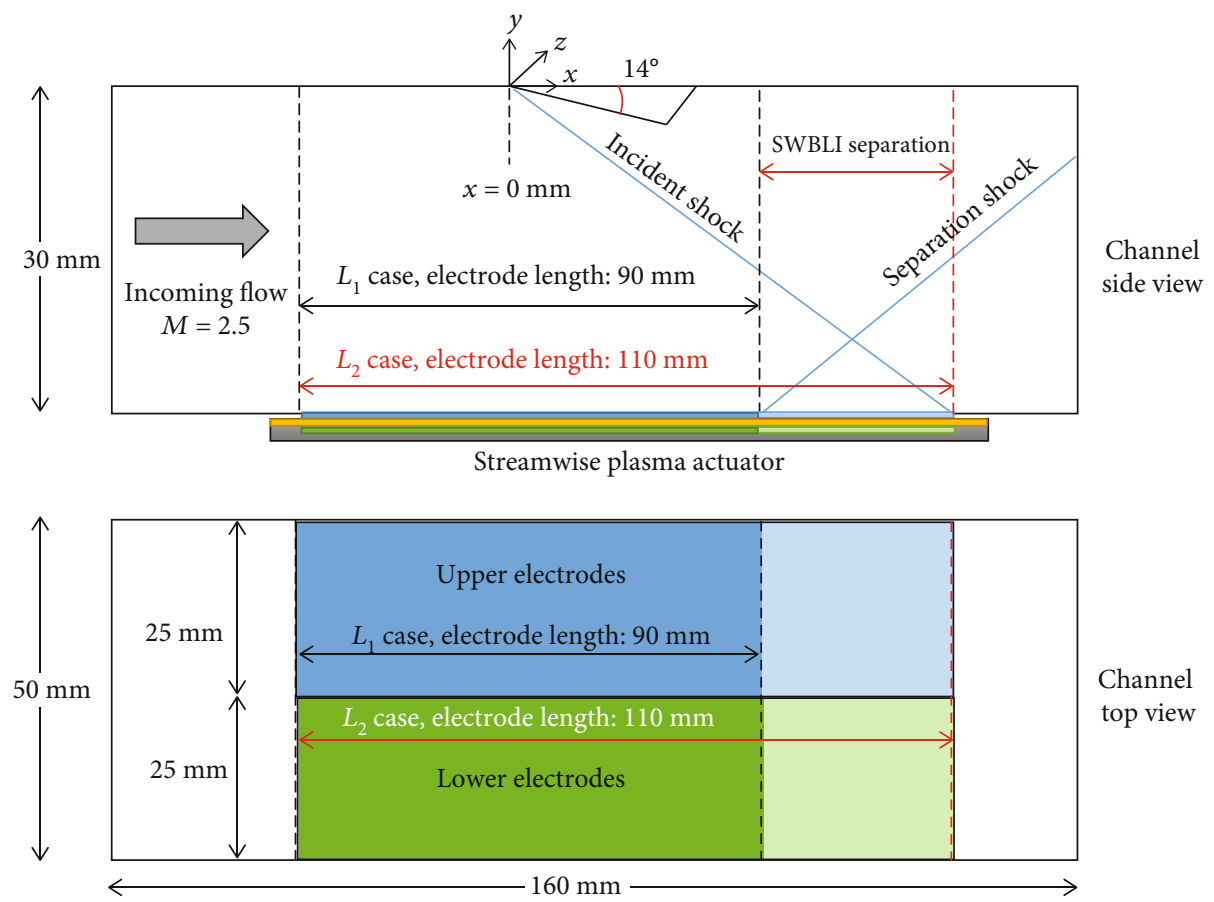

(c) Electrode configuration

Figure 4: Continued. 


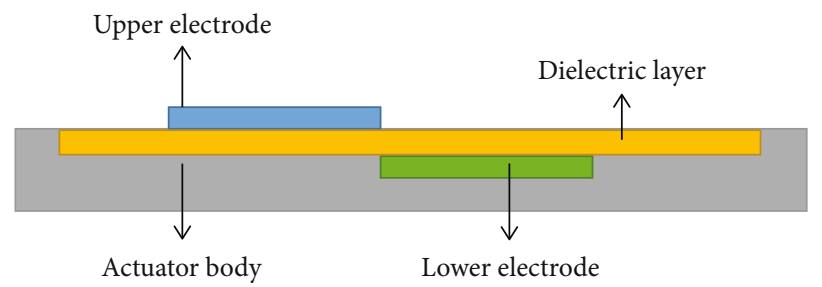

(d) Component of proposed NS-DBD plasma actuator

Figure 4: The actuator arrangements and plasma discharge region: (a) $L_{1}$ test case, (b) $L_{2}$ test case, (c) electrode configuration for $L_{1}$ and $L_{2}$ cases, and $(\mathrm{d})$ introduction of NS-DBD components at a section perpendicular to the direction of flow.

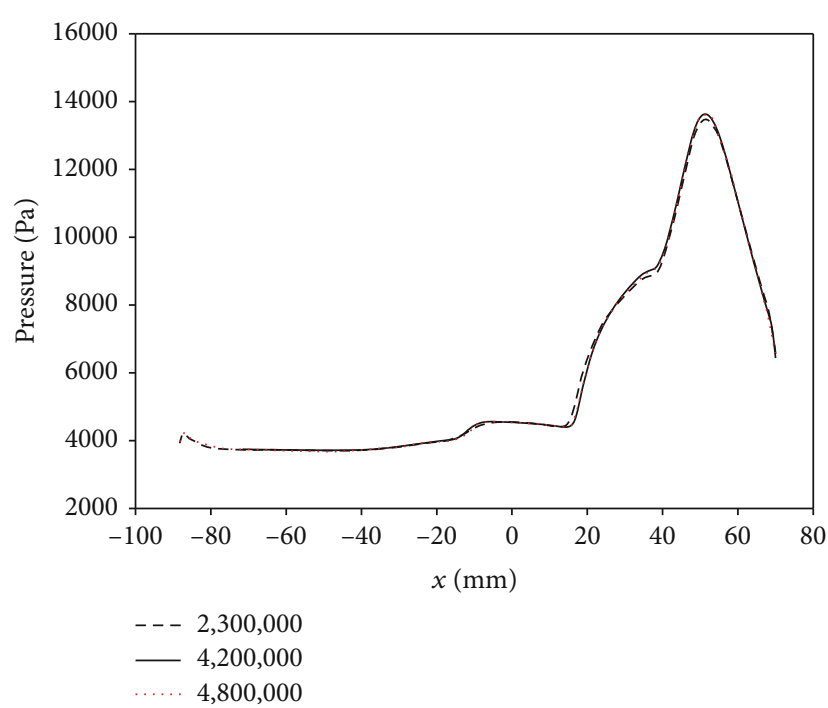

(a) Grid independence study

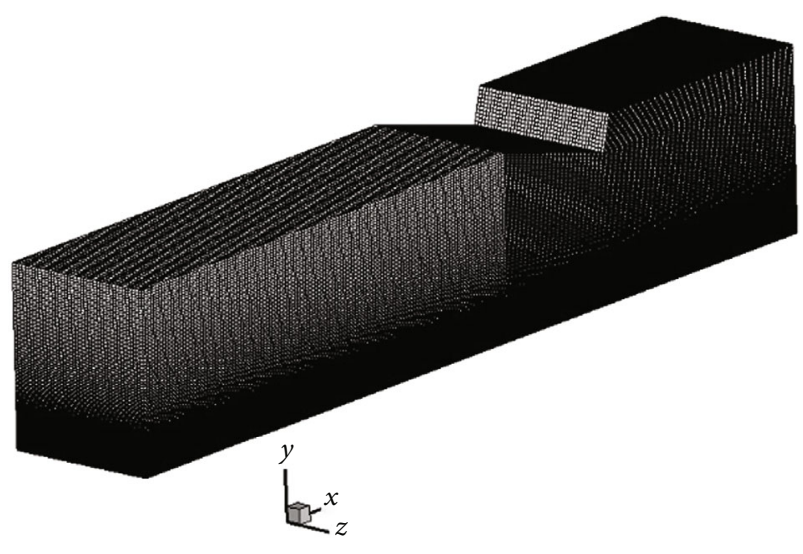

(b) Applied computational grid

Figure 5: Applied computational grid in the computational domain.

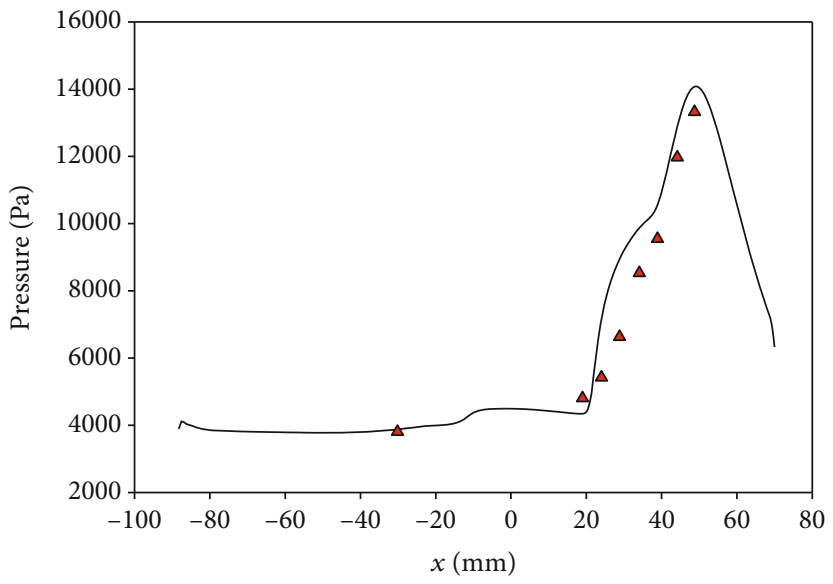

- Current results

$\Delta$ Kinefuchi et al.

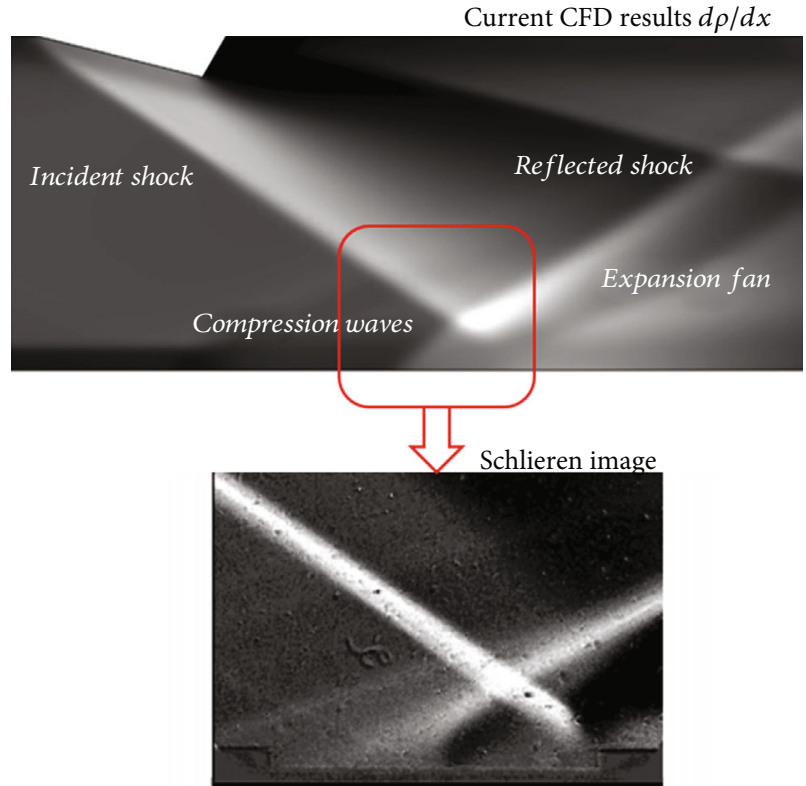

(b) Density distribution

(a) Static pressure distribution

FIGURE 6: Verification of current numerical results. 
calculation, the convergence of the numerical solution is assured by monitoring the scaled residuals to a constant level below $10^{-3}$ and $10^{-6}$, respectively. Time step in solving unsteady flows was considered to be $10^{-6}$. Figure 3 presents the schematic of the studied geometry. According to the figure, a shock generator or a compression ramp was positioned $14^{\circ}$ to the flow axis. The boundary conditions of "inlet pressure" and "outlet pressure" were applied in inlet and outlet sections, respectively. Based on the no-slip condition, wall velocity was considered to be zero.

The sequences of the plasma heated layer by NS-SDBD are transfer of energy to electrons, ionization of the atoms and molecules by electrons, and recombination and encounter between particles resulting in exchange or transformation of energy and finally release of the energy to the flow. As the abovementioned process needs less than $1 \mu$ s to consummate, it is ignored in simulation and the phenomenological model of temperature distribution of actuators is applied to the solution. In this regard, the plasma region was simulated by applying the temperature distribution presented as Equations (5) and (6) and based on an energy deposition-consistent phenomenological model. As the following equation, $\Delta T$ is applied to the plasma discharge region. It is assumed that the temperature distribution in the plasma discharge region is in the form of radial and has a Gaussian profile [31]:

$$
\frac{\Delta T}{T_{\text {ref }}}=\exp \left[-n\left(\frac{r}{R}\right)^{2}\right] .
$$

The temperature of the plasma discharge region is associated with $Q$ (energy deposition model) by the flowing relation:

$$
Q=\int \rho C_{v} \Delta T d V
$$

where $r$ is the radial coordinate and $R$ is the radius of the $1 / 4$ cylinder, $20 \mathrm{~mm}$. $\rho$ is air density, $C_{v}$ is specific heat at constant volume of air, and $d V$ is volume element in the plasma region. The deposited energy $Q$ is set to $50 \mathrm{~mJ}$ in reference to the experiment [31].

Figure 3 shows the computational domain of the present study and applied boundary conditions. As shown in the figure, a shock generator or a compression ramp was positioned at $14^{\circ}$ to the flow axis. The channel width, height, and length are set to $50 \mathrm{~mm}, 30 \mathrm{~mm}$, and $160 \mathrm{~mm}$, respectively, according to the experiment. The $x=0$ position was exactly set to the start point of the shock generator. The boundary conditions of "pressure inlet" and "pressure outlet" were applied to inlet and outlet planes, respectively. Based on the no-slip condition, wall velocity was considered to be zero. It should be noted that the plain at $x=-70 \mathrm{~mm}$ is intended for the starting location of the actuator's electrodes, while the plains at $x=20 \mathrm{~mm}$ and $x=40 \mathrm{~mm}$ are considered the end location of electrodes for the two test cases which are presented as $L_{1}$ and $L_{2}$ in Figure 4.

The configurations of streamwise NS-DBD plasma actuators and schematic of the temperature profile applied to the

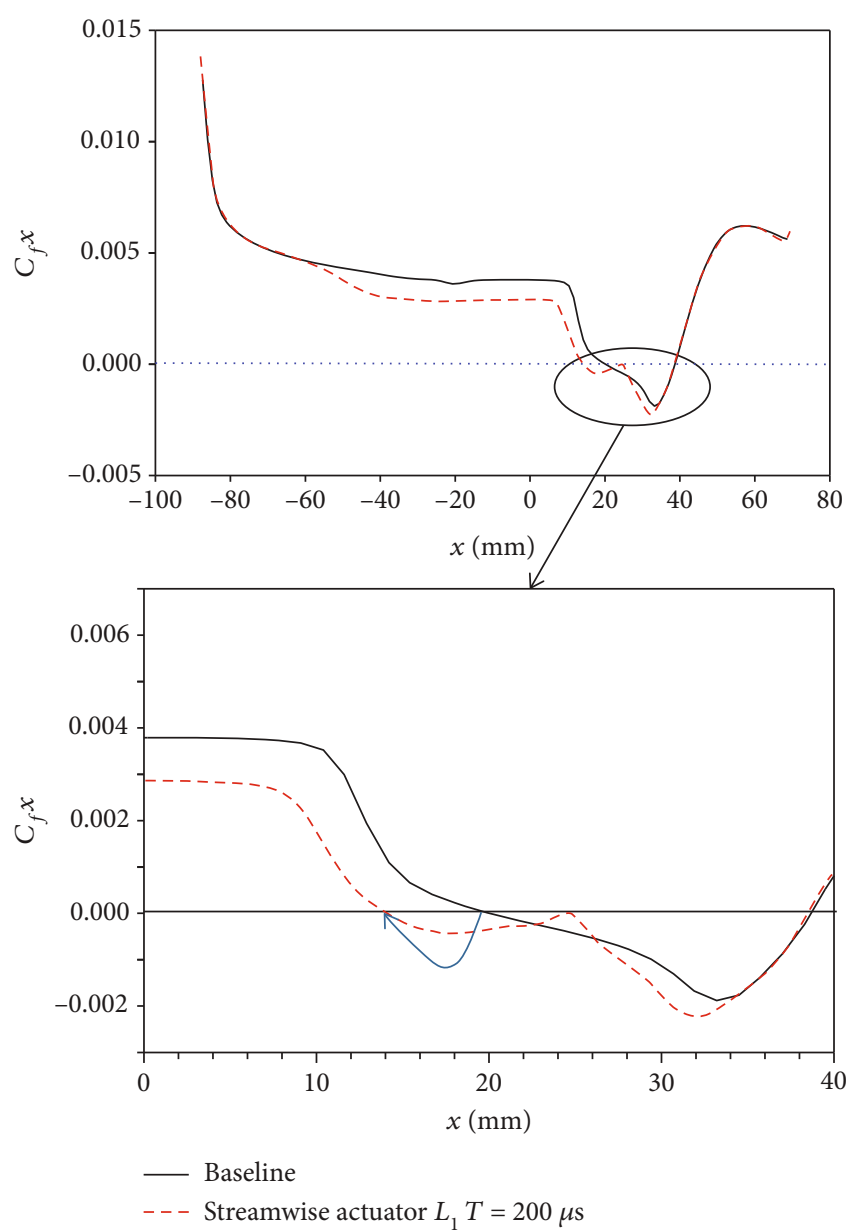

FIgURE 7: Distribution of friction factor in flow-direction component, plasma discharge length $\left(L_{1}\right)$.

plasma discharge region are described in Figure 4. In the streamwise type, the electrodes are installed parallel to the core flow (along with the incoming flow). According to Figures 4(a) and 4(b), in order to evaluate plasma actuation effects, various discharge lengths are considered: test case number 1 (with $L_{1}=90 \mathrm{~mm}$ ) and test case number 2 (with $L_{2}=110 \mathrm{~mm}$ ). For the case 1 actuation, the plasma discharge is limited to the position of $x=20 \mathrm{~mm}$ (as the start point of flow separation), and for the case 2 , the discharge length is extended to the end of the separation region at $x=40 \mathrm{~mm}$. Considering the abovementioned discharging lengths, we are able to evaluate the effect of parallel plasma discharge lenght on SWBLI control. The details of the actuator configurations for both $L_{1}$ and $L_{2}$ test cases are presented in Figure $4(\mathrm{c})$. The figure gives detailed information on the computational domain from the top and side views, coordination system, actuator location, and their dimensions as well.

\section{Grid Independency}

The number of elements could leave a significant impact on the accuracy of numerical simulations. To assess this, simulations were conducted for different numbers of elements. 

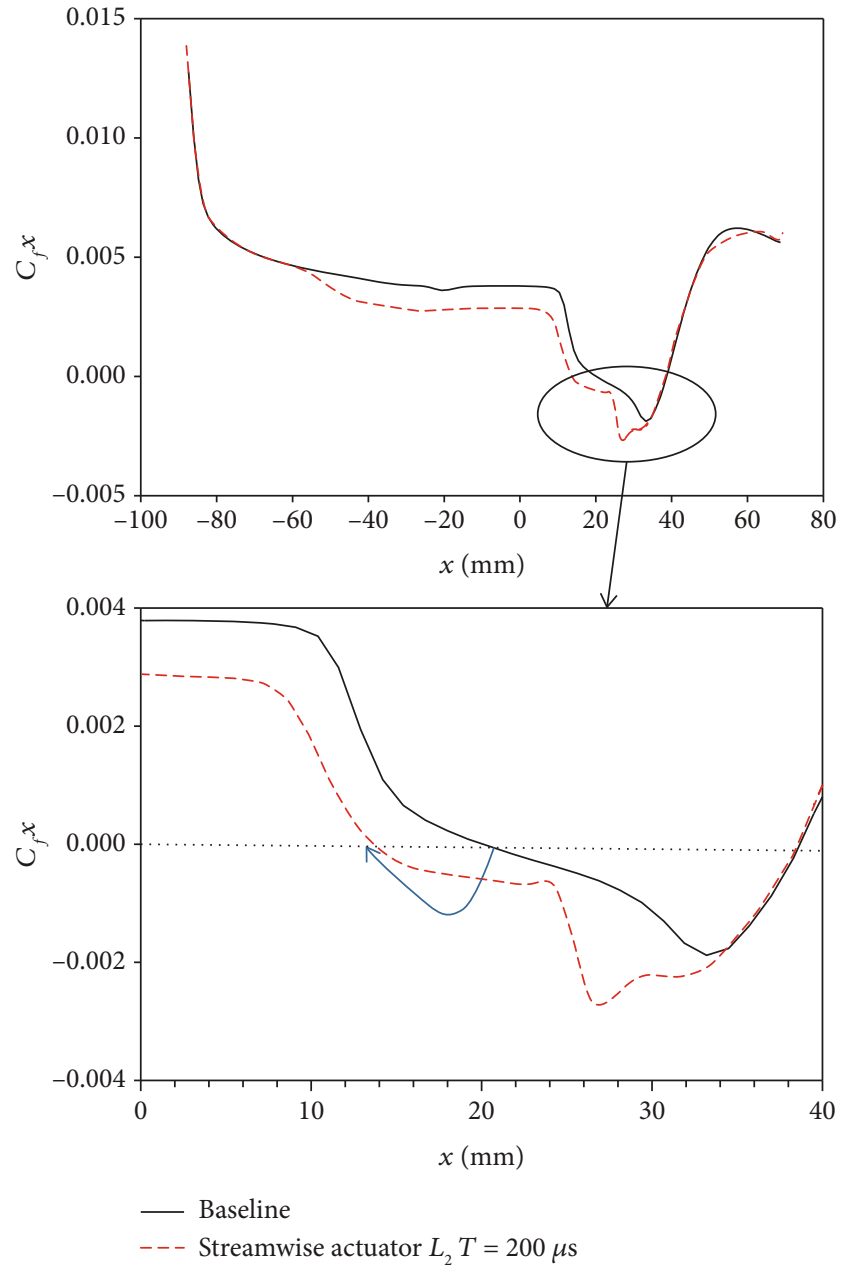

Figure 8: Distribution of friction factor in flow-direction component, plasma discharge length $\left(L_{2}\right)$.

Figure 5(a) compares the distribution of pressure for different numbers of elements. According to the figure, when the number of elements exceeded 4200000 , there was no significant change in numerical results (variation $<2 \%$ ). Therefore, the same number of elements (4200000) was used to perform all the simulations. Figure 5(b) exhibits the computational grid used in this study. According to the figure, the structured mesh is applied. To increase the accuracy of the numerical results near the bottom wall, the element size (in the SWBLI region) is set smaller than the upper wall.

\section{Verification of Numerical Results}

The results of the Kinefuchi et al. [31] study were used to assure the accuracy of numerical results. Figure 6(a) compares the distribution of pressure on the wall between the studied flow $(\mathrm{Mach}=2.8)$ and that of Kinefuchi et al. [31]. Figure 6(a) illustrates that there is a good agreement between the present numerical results and the experimental tests. Therefore, it can be argued that the numerical solution has acceptable accuracy. The image taken from the variation of flow density $(d \rho / d x)$ of numerical solution at the middle plan of the domain is presented in Figure 6(b) in comparison to

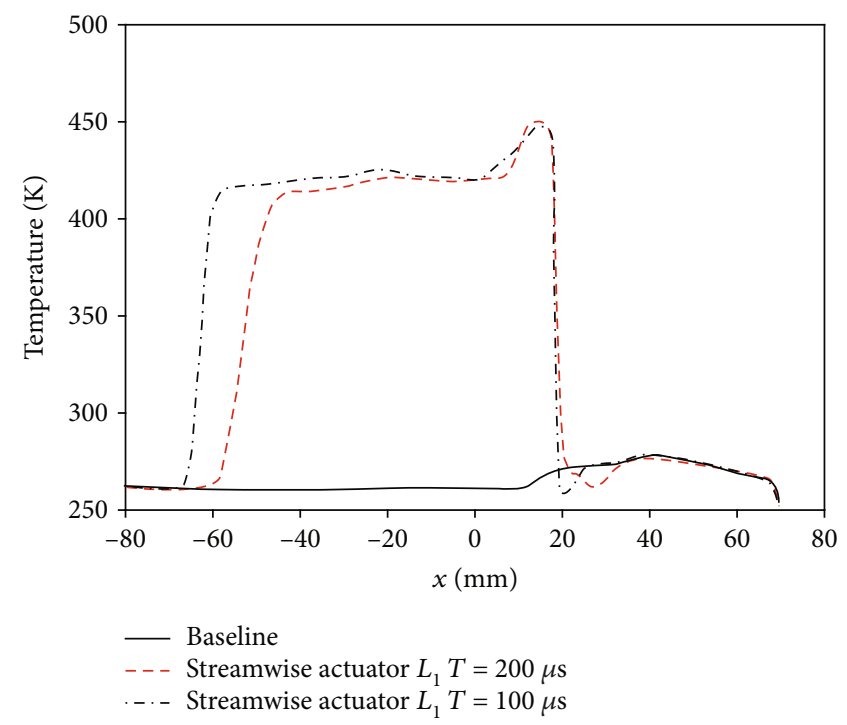

FIGURE 9: Distribution of temperature over the surface, plasma discharge length $=L_{1}$.

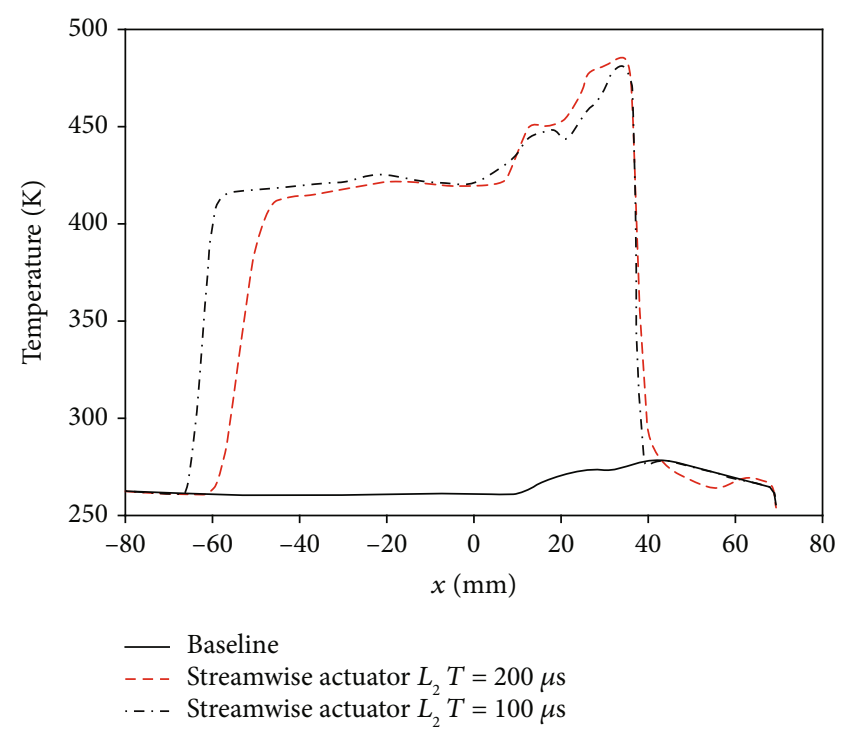

FIGURE 10: Distribution of temperature over the surface, plasma discharge length $=L_{2}$.

the schlieren image from the experiment of Kinefuchi et al. [31]. Comparison of both pictures shows acceptable simulation accuracy. In both pictures, an oblique shock angle is approximately $33.2^{\circ}$.

\section{Results and Discussions}

In this study, the flow field of supersonic flow (Mach number 2.5) passing a shock generator (14 degrees) is simulated. In this section, by presenting quantity and quality results, the effect of the length of the plasma discharge region on the flow field and SWBLI has been studied. 
Temperature (K)
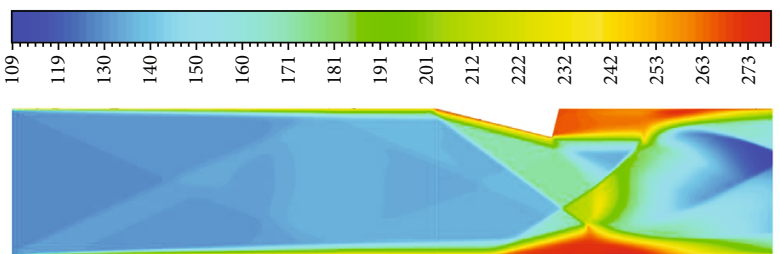

Baseline (no actuation)

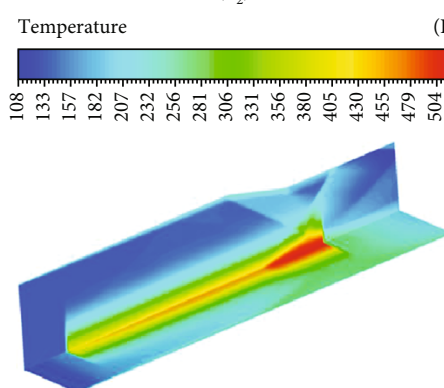

$\left(L_{1}\right)$

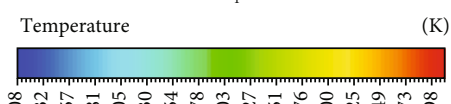

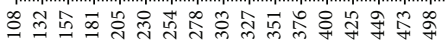

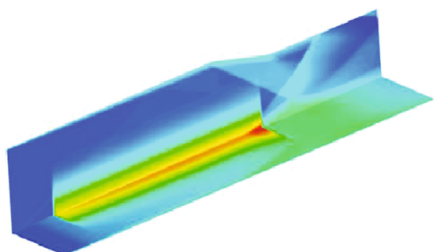

$\overbrace{}^{y} \nearrow^{x}$

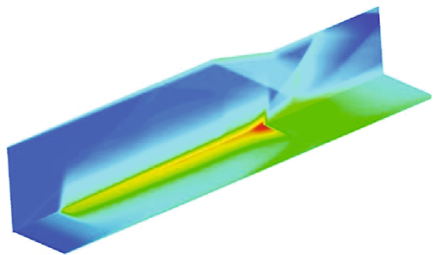

$\left(L_{1}\right)$

Time: $15 \mu \mathrm{s}$

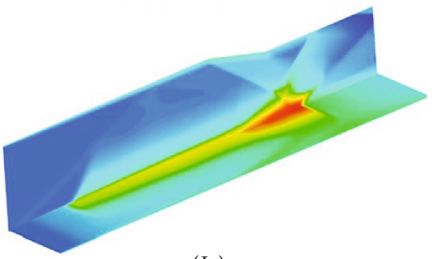

$\left(L_{2}\right)$

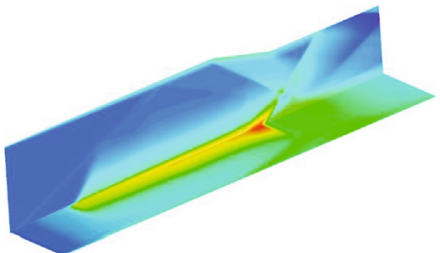

$\left(L_{1}\right)$

Time: $60 \mu \mathrm{s}$

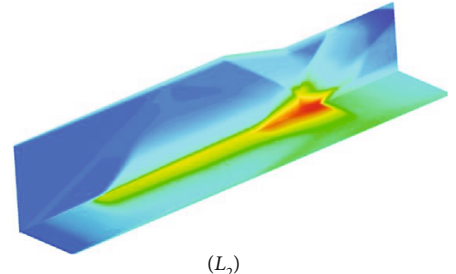

Time: $100 \mu \mathrm{s}$

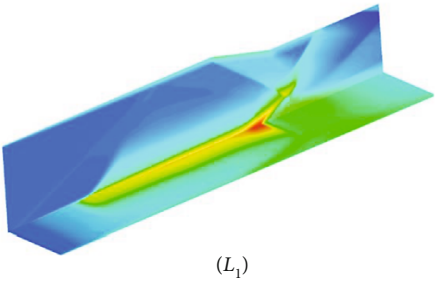

$\left(L_{1}\right)$

Figure 11: Contour of the temperature distribution over the surface plasma discharge lengths $=L_{1}$ and $L_{2}$.

Figure 7 indicates the distribution of the friction factor on the wall at the centerline of the channel when the end of the plasma discharge length extends to the start of the separation point $\left(L_{1}\right)$ and after 200 microseconds when plasma is turned on and compares it with baseline flow (without plasma actuation). According to definitions, friction factors $<0$ indicate flow separation and existence of separation bubbles [32] According to Figure 7, when the plasma actuator was applied from its start point $(x=-70 \mathrm{~mm})$, the magnitude of wall shear stress decreased. Without plasma actuation, flow separation occurred at $x=20 \mathrm{~mm}$ and the flow reattached to the surface at $x=39 \mathrm{~mm}$. In other words, in the absence of a 


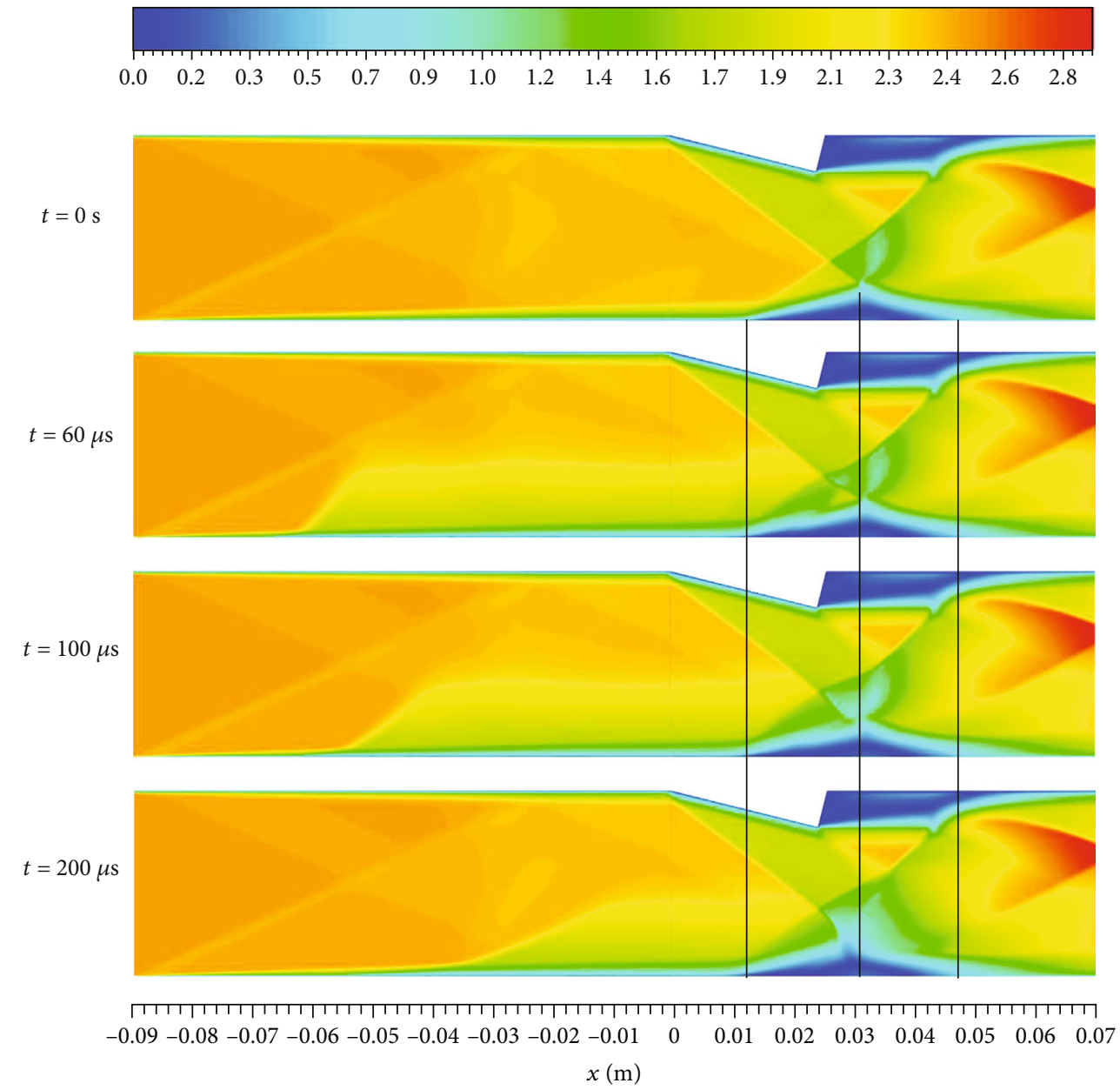

FIgURE 12: Contour of the Mach number distribution, plasma discharge length $=L_{1}$.

plasma actuator, the length of separation bubbles was $19 \mathrm{~mm}$. According to results, plasma discharge shifted flow separation to the upstream, and flow separation occurred at $x=14 \mathrm{~mm}$. Investigating the reattachment point shows that the flow could overcome the adverse pressure gradient at $x=22 \mathrm{~mm}$ and reattached to the surface. However, the momentum of supersonic flow is not sufficient to keep the flow attached to the surface. Therefore, it separated again and reattached to the surface at $x=39 \mathrm{~mm}$. In the other words, when plasma actuator length extended to the start point of separation, it shifted the start point of separation to the upstream and the formed separation bubbles reshaped so that it was divided into two separation bubble regions.

Figure 8 presents the distribution of the friction factor on the wall at the centerline of the channel when the end of plasma discharge length extends to the end of the separation point $\left(L_{2}\right)$ and compares it with the baseline flow. It means the plasma actuation is extended into the SWBLI. According to Figure 8, the plasma actuation shifted the separation point to the upstream similar to the discharge length $L_{1}$. The displacement of the separation bubble is due to the movement of the reflected shock position [33]. In fact, due to the plasma discharge, the shock position moves upstream and changes the position of the separation bubble.
Investigating the variation of the friction factor inside the separation region showed that increasing the length of the plasma actuator to $L_{2}$ changed the structure of the separation bubble so that the value of the friction factor differed from that of $L_{1}$ length. In the case of $L_{2}$, the flow reattached to the surface at the end of the separation bubble, and the larger bubbles were generated. The investigation of the minimum friction factor showed that the friction factor decreased when plasma discharge length increased from $L_{1}$ to $L_{2}$, and it makes the SWBLI separation stronger. The main reason for this phenomenon is the addition of energy discharged by the plasma actuator in the region of SWBLI.

Figures 9 and 10 illustrate the effect of plasma discharge length on the distribution of temperature at different time periods. According to the figures, surface temperature increased under the influence of plasma discharge and deposited energy. The comparison of the maximum temperature rises between plasma actuators with discharge lengths $L_{1}$ and $L_{2}$ showed that the maximum temperature of the surface increased from $450 \mathrm{~K}$ to $480 \mathrm{~K}$ by the increase of plasma discharge length.

Figure 11 demonstrates the distribution of flow temperature at different periods for the studied two discharge lengths. In Figure 11, the initial temperature distribution which 


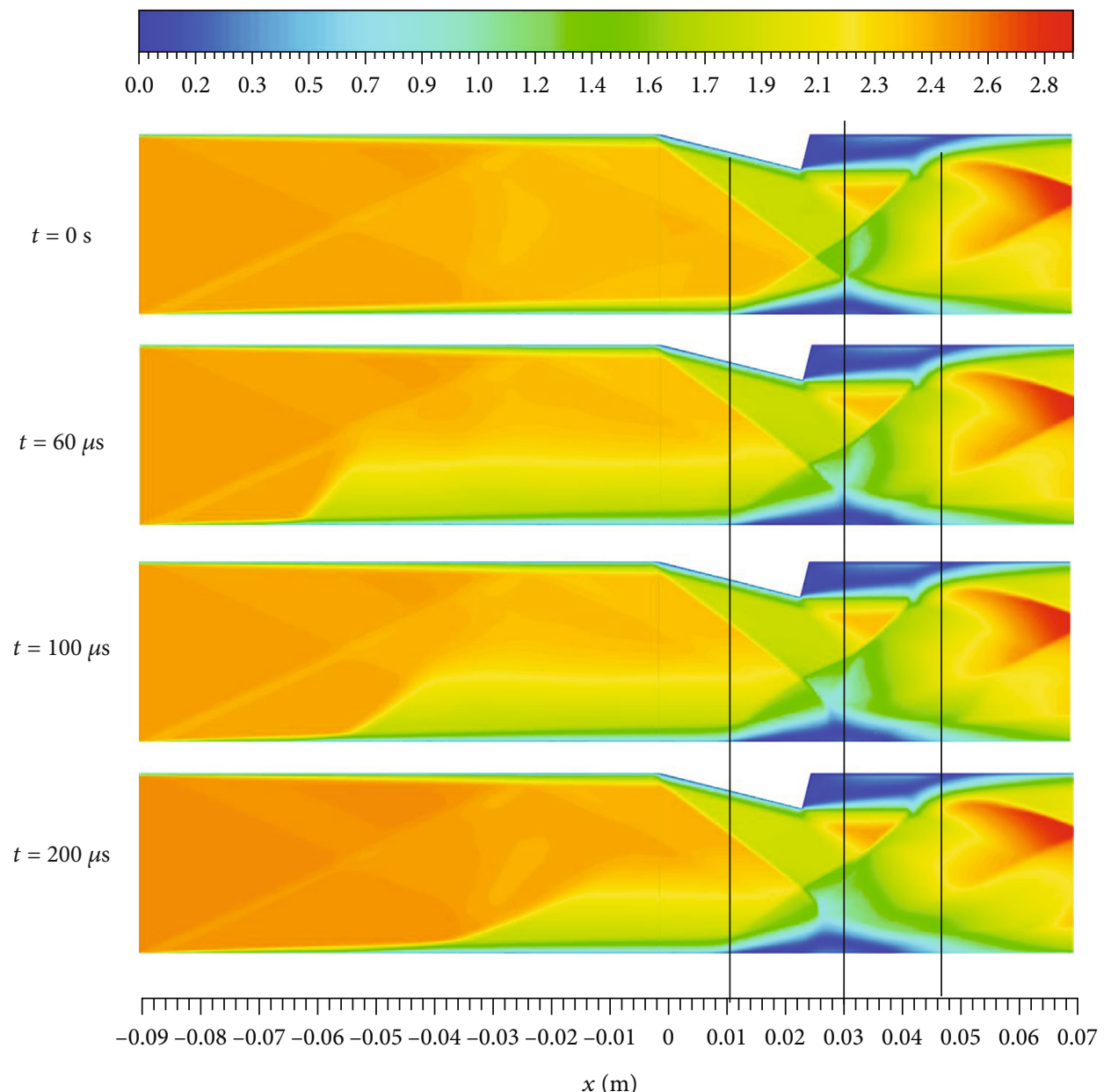

FIgURE 13: Contour of the Mach number distribution, plasma discharge length $=L_{2}$.

simulates the flow thermalization by NS-SDBD plasma is shown. As the electrodes of the plasma actuator are parallel to the flow, that temperature distribution is parallel to the flow velocity vector. According to the presented contours, in the baseline flow, the temperature distribution was under the influence of incident shock, separation shock, and reflected shock and SWBLI increased the inside temperature of the separation bubble with the maximum value of $273 \mathrm{~K}$. According to the results, discharge length $L_{1}$ (extended to the start of separation bubble) affected temperature distribution and increased it up to $446 \mathrm{~K}$. Over time, the high temperature region generated by the actuator moves with the flow stream: the speed of the high temperature region in the boundary layer is slow, while it propagates faster in the core flow. It should be noted that the high temperature region lowers the flow speed and Mach number, and that causes the SWBLI region to become larger with the high temperature region flowing into it.

The investigation of the temperature distribution for discharge length $L_{2}$ showed that flow temperature increased to $482 \mathrm{~K}$ compared to the previous state $\left(L_{1}\right)$. The increased temperature in the SWBLI region lowers the flow speed and Mach number, and that increases the tendency of the flow to separate. Consequently, the SWBLI became stronger more than the $L_{1}$ case.
The Mach number distribution for two plasma discharge lengths at different time periods after plasma actuation is described in Figures 12 and 13. According to the figures, the Mach number decreased in the plasma-affected region and the angle of separation shock increased. Besides, the numerical result shows that the high temperature region generated by the actuator moves with the flow stream. It can be seen that the speed of the high temperature region in the boundary layer is slow, while it moves faster in the core flow. On the other hand, the heated region produced by the NS-DBD plasma actuator lowers the flow speed and Mach number, makes the boundary layer thickness thicker, and shifts the separation shock wave upstream.

To investigate the structures of sonic line and separation bubbles generated under the influence of the plasma actuation, the contour of velocity distribution in the $x$-direction is shown in Figure 14. The solution results were evaluated at different time periods after the plasma actuator was turned on. It is noted that values $<0$ indicate flow recirculation and the position of separation bubbles. According to the literature review, whenever the height of the sonic line increases, the length of the separation region will be increased [34].

According to Figure 14, the sonic line and separation bubble were affected by plasma discharge. The results reveal 


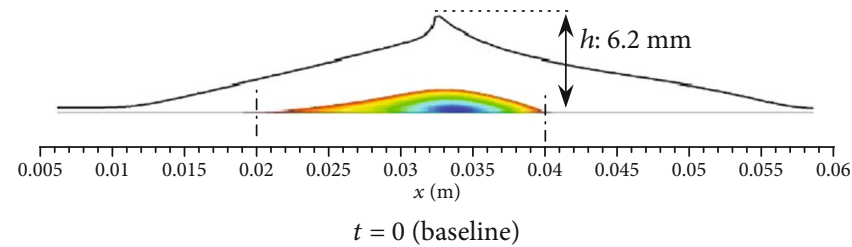

Velocity $u$
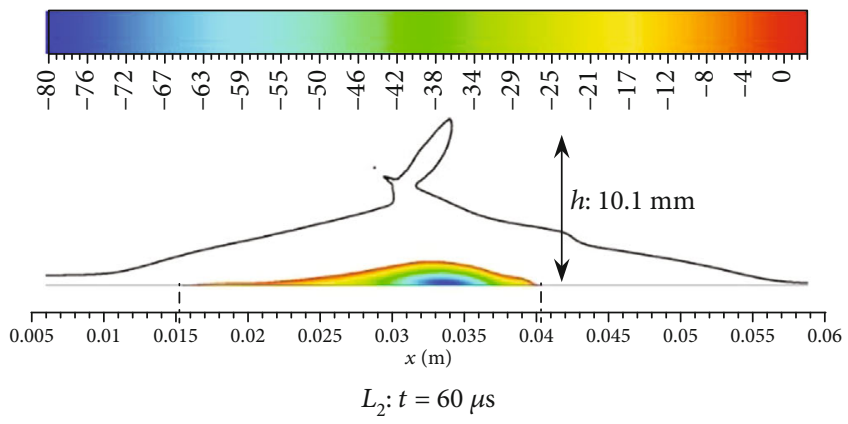

Velocity $u$
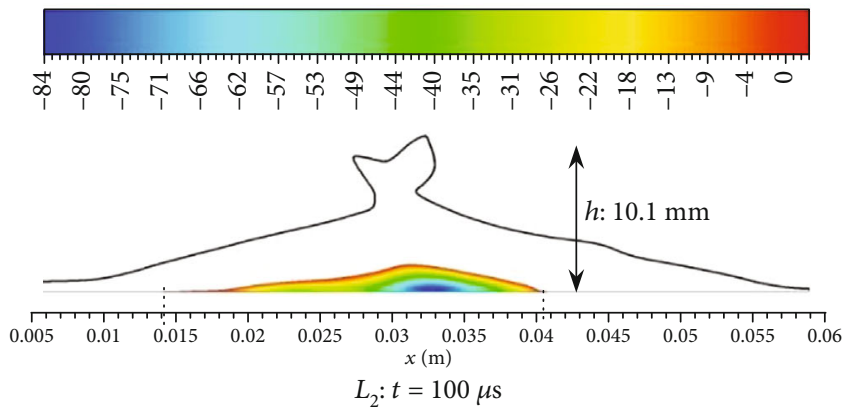

Velocity $u$

$\left(\mathrm{m} \mathrm{s}^{-1}\right)$
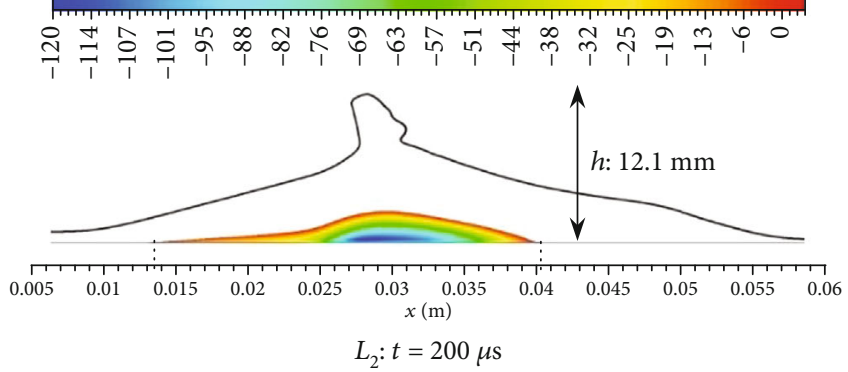

Velocity $u$

$\left(\mathrm{m} \mathrm{s}^{-1}\right)$

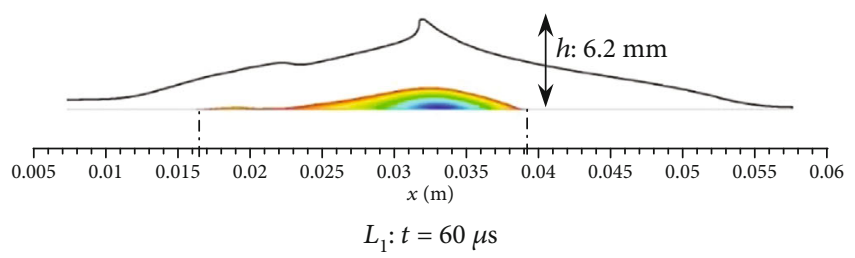

Velocity $u$
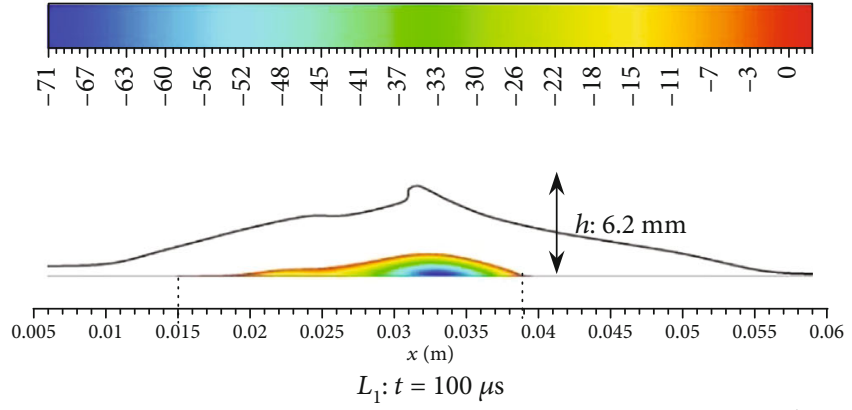

Velocity $u$ $\left(\mathrm{m} \mathrm{s}^{-1}\right)$
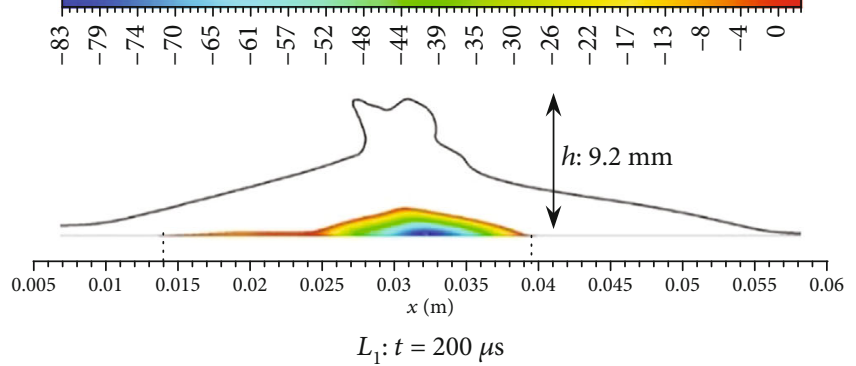

FIGURE 14: Structures of the sonic line and separation bubbles.

that there is no significant difference in the end point of flow separation and the point of flow reattachment to the surface between baseline and actuated cases, whereas plasma actuation shifted the start of flow separation to the upstream and increased the length of separation bubbles. In addition, the Mach number decreased under the influence of the plasma-affected region. That increased the size of separation bubbles and strengthened flow recircula- tion to the bubbles. Investigating the velocity of the recirculation zone showed in the longer discharge length $\left(L_{2}\right)$, the magnitude of the reverse flow velocity increased. The velocity of the reverse flow was $-71,-83$, and $-120 \mathrm{~m} / \mathrm{s}$ in the baseline and actuated condition with discharge lengths of $L_{1}$ and $L_{2}$, respectively. The intersection of incident shock and reflected shock in the bottom wall was considered to be SWBLI height. 


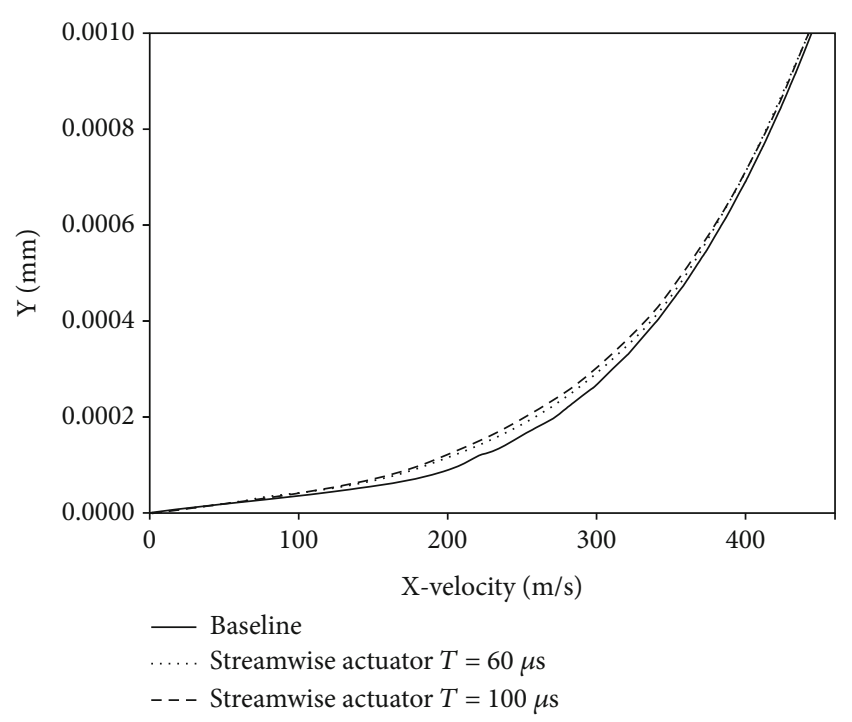

FIGURE 15: Velocity profile in the boundary layer (at $x=-20 \mathrm{~mm}$ ).

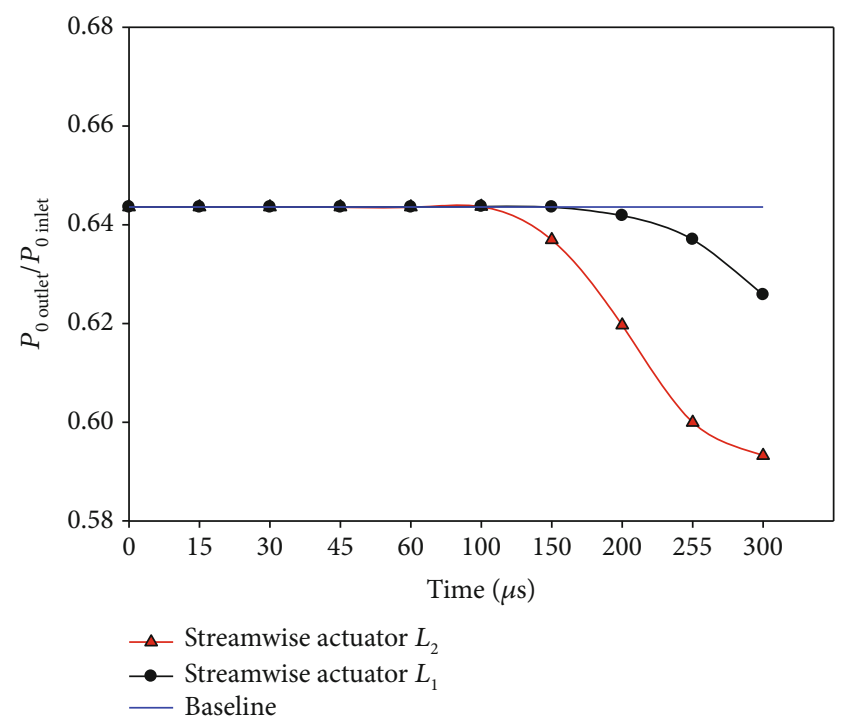

FIGURE 16: Variations of pressure recovery coefficient versus time in two different discharge regions.

Investigating the specifications of SWBLI height in Figure 14 shows that when discharge length extended to the end of the separation bubble $\left(L_{2}\right)$, SWBLI height increased and the sonic line moved away from the wall. The increase of SWBLI height increased the length of the separation bubbles and strengthened the recirculation flow. According to the results, applying the plasma actuator with discharge length $L_{1}<100 \mu$ s did not affect the height of the sonic line while after $100 \mu \mathrm{s}$, the distance of the sonic line from the surface increased from 6 to $10 \mathrm{~mm}$. This, in turn, increased the length of the separation bubble and strengthened flow recirculation into the separation bubbles.

The increase in sonic line elongation and the increase in separation bubble length by plasma discharge heating are due to the increase in layer thickness. In this regard, the velocity profile inside the boundary layer (at $x=-20 \mathrm{~mm}$ ) in the middle of the plasma discharge region is shown in Figure 15. As can be seen in the figure, under the influence of plasma discharge and at the same distance from the bottom wall, the flow velocity decreased. This indicates that the area affected by the momentum force is reduced and the velocity profile is affected by the shear stress. It should be mentioned that increasing the thickness of the boundary layer increases the area affected by viscosity and decreases the pressure recovery coefficient, which is described in Figure 16.

Figure 16 shows the effects of strengthened recirculation flow and increased length of the separation bubbles on the pressure recovery coefficient. The figure illustrates that when SWBLI was strengthened by the plasma actuator, the pressure recovery coefficient decreased. From the variations of the pressure recovery coefficient, it could be concluded that the plasma actuator with discharge length $L_{2}$ had a significant effect on total pressure drop. Therefore, the use of actuators with longer discharge lengths extending to the end of separation bubbles is not recommended.

\section{Conclusion}

The purpose of the current study was to investigate the control mechanism of NS-DBD in supersonic flow, heating and momentum transferring to the flow, and their effects on the SWBLI separation region and location of the separation shock wave. As mentioned before, the amount of two effects of the NS-SDBD plasma is directly related to the electrode configuration of the plasma actuator. The electrode configuration will result in vorticity generation and consequently momentum transferring to the boundary layer or only heating to the supersonic flow and its consequences. In this regard, the effects of the streamwise application of NS-DBD plasma actuators were investigated and numerically analyzed in a Mach 2.5 supersonic flow passing a $14^{\circ}$ shock generator. 3D numerical simulations were conducted for different plasma discharge lengths $\left(L_{1}\right.$ and $\left.L_{2}\right)$ in the supersonic flow. Two plasma discharge lengths were studied in order to compare the effects of NS-DBD-induced energy to the upstream and inside of SWBLI. In order to achieve the goals of the study, the baseline simulation (without plasma actuation) was carried out, and then, the streamwise NS-DBD plasma actuator model was used as an initial condition according to Equations (5) and (6). It should be noted that only one burst/pulse was considered in the numerical simulations. Using two lengths of plasma discharge showed that heating in the region of SWBLI ( $L_{1}$ case) increased the temperature of the interaction region compared to length $L_{1}$ and baseline flow. This phenomenon caused lower flow velocity in the SWBLI region and increased the heat transfer coefficient between the deposited energy, and the flow underpinned the rise of temperature. This, in turn, increased the velocity of flow recirculation in the SWBLI region compared to discharge length $L_{1}$ and the baseline flow. It seems that using a different configuration of NS-DBD, e.g., spanwise actuation, could be more efficient in order to transfer momentum to 
the boundary layer and consequently reduce the separation length of SWBLI.

All in all, the numerical results showed that the high temperature region generated by the plasma actuator propagates in the passing flow and lowers the Mach number, and that causes the SWBLI region and separation length to become larger with the high temperature region flowing into it. The results also revealed that the main mechanism of used configuration for the plasma actuator (streamwise type) is only boundary layer heating. Consequently, the boundary layer heating made the size of the separation bubble increased, the SWBLI stronger, and the boundary layer thicker. But the heating was successful to control the separation shock position and move it upstream by $6 \mathrm{~mm}$. This indicates the potential of the use of these actuators in supersonic intakes for reaching starting condition of intake and optimization of oblique shock wave system.

\section{Data Availability}

The numerical data used to support the findings of this study are included within the article.

\section{Conflicts of Interest}

The authors declare that they have no conflicts of interest.

\section{References}

[1] D. S. Dolling, "Fifty years of shock-wave/boundary-layer interaction research: what next?" AIAA Journal, vol. 39, no. 8, pp. 1517-1531, 2001.

[2] Y. Tao, W. D. Liu, X. Q. Fan, and Y. L. Zhao, "Structural characteristics of the shock-induced boundary layer separation extended to the leading edge," Physics of Fluids, vol. 29, no. 7, p. 071701, 2017.

[3] S. B. Verma and C. Manisankar, "Control of a Mach reflectioninduced interaction using an array of vane-type vortex generators," Shock Waves, vol. 28, no. 4, pp. 815-828, 2018.

[4] S. Pirozzoli and F. Grasso, "Direct numerical simulation of impinging shock wave/turbulent boundary layer interaction at M=2.25," Physics of Fluids, vol. 18, no. 6, p. 065113, 2006.

[5] R. Saad, E. Erdem, L. Yang, and K. Kontis, "Experimental studies on micro-ramps at Mach 5 BT -," in 28th International Symposium on Shock Waves, K. Kontis, Ed., pp. 861-866, Springer, Berlin Heidelberg, Berlin, Heidelberg, 2012.

[6] A. N. Smith, H. Babinsky, J. L. Fulker, and P. R. Ashill, "Shock wave/boundary-layer interaction control using streamwise slots in transonic flows," Journal of Aircraft, vol. 41, no. 3, pp. 540-546, 2004.

[7] M. N. Sarimurat and T. Q. Dang, "Shock management in diverging flow passages by blowing/suction, part 2: applications," Journal of Propulsion and Power, vol. 28, no. 6, pp. 1230-1242, 2012.

[8] F. Falempin, E. Wendling, M. Goldfeld, and A. Starov, "Experimental investigation of starting process for a variable geometry air inlet operating from Mach 2 to Mach 8," in 42nd AIAA/ASME/SAE/ASEE Joint Propulsion Conference \& Exhibit, California, USA, 2006.

[9] J. Huang, B. Hu, Z. Li, J. Zhang, Z. Qian, and S. Lan, "The effects of plasma-based body force on flow separation suppression BT-," in Advances in Effective Flow Separation Control for Aircraft Drag Reduction: Modeling, Simulations and Experimentations, N. Qin, J. Periaux, and G. Bugeda, Eds., pp. 113-129, Springer International Publishing, Cham, 2020.

[10] G. Tathiri, H. Parishani, S. G. Pouryoussefi et al., "Experimental investigation of separation control on a Naca0024 airfoil using stationary and non-stationary AC-dielectric barrier discharge plasma actuator," Journal of Applied Fluid Mechanics, vol. 9, pp. 877-888, 2016.

[11] S. G. Pouryoussefi, M. Mirzaei, F. Alinejad, and S. M. Pouryoussefi, "Experimental investigation of separation bubble control on an iced airfoil using plasma actuator," Applied Thermal Engineering, vol. 100, pp. 1334-1341, 2016.

[12] X. Meng, H. Hu, C. Li, A. A. Abbasi, J. Cai, and H. Hu, "Mechanism study of coupled aerodynamic and thermal effects using plasma actuation for anti-icing," Physics of Fluids, vol. 31, 2019.

[13] K. Kinefuchi, A. Y. Starikovskiy, and R. B. Miles, "Numerical investigation of nanosecond pulsed plasma actuators for control of shock-wave/boundary-layer separation," Physics of Fluids, vol. 30, 2018.

[14] B. K. Mishra and P. K. Panigrahi, "Flow field induced by a dielectric barrier discharge plasma actuator analyzed with biorthogonal decomposition," Physics of Fluids, vol. 32, 2020.

[15] C. Anzalotta, K. Joshi, E. Fernandez, and S. Bhattacharya, "Effect of forcing the tip-gap of a NACA0065 airfoil using plasma actuators: a proof-of-concept study," Aerospace Science and Technology, vol. 107, p. 106268, 2020.

[16] C. Kolbakir, H. Hu, Y. Liu, and H. Hu, "An experimental study on different plasma actuator layouts for aircraft icing mitigation," Aerospace Science and Technology, vol. 107, p. 106325, 2020.

[17] A. S. Taleghani, A. Shadaram, M. Mirzaei, and S. Abdolahipour, "Parametric study of a plasma actuator at unsteady actuation by measurements of the induced flow velocity for flow control," Journal of the Brazilian Society of Mechanical Sciences and Engineering, vol. 40, no. 4, p. 173, 2018.

[18] R. Khoshkhoo and A. Jahangirian, "Flow separation control over airfoils using DBD plasma body force," Journal of the Brazilian Society of Mechanical Sciences and Engineering, vol. 38, no. 8, pp. 2345-2357, 2016.

[19] D. Opaits, D. Roupassov, S. Starikovskaia, A. Starikovskii, I. Zavialov, and S. Saddoughi, "Plasma control of boundary layer using low-temperature non-equilibrium plasma of gas discharge," in 43rd AIAA Aerospace Sciences Meeting and Exhibit, Nevada, USA, 2005.

[20] D. V. Roupassov, A. A. Nikipelov, M. M. Nudnova, and A. Y. Starikovskii, "Flow separation control by plasma actuator with nanosecond pulse periodic discharge," Journal of AIAA, vol. 47, no. 1, pp. 168-185, 2012.

[21] M. Nishihara, K. Takashima, J. W. Rich, and I. V. Adamovich, "Mach 5 bow shock control by a nanosecond pulse surface dielectric barrier discharge," Physics of Fluids, vol. 23, 2011.

[22] J. G. Zheng, Z. J. Zhao, J. Li, Y. D. Cui, and B. C. Khoo, "Numerical simulation of nanosecond pulsed dielectric barrier discharge actuator in a quiescent flow," Physics of Fluids, vol. 26, 2014.

[23] B. Wei, Y. Wu, H. Liang et al., "Performance and mechanism analysis of nanosecond pulsed surface dielectric barrier discharge based plasma deicer," Physics of Fluids, vol. 31, 2019.

[24] G. Song, J. Li, and M. Tang, "Direct numerical simulation of the pulsed arc discharge in supersonic compression ramp 
flow," Journal of Thermal Science, vol. 29, no. 6, pp. 15811593, 2020.

[25] J. Sheng, Y. Wu, H. Zhang, Y. Wang, and M. Tang, "Flow control effect of spanwise distributed pulsed arc discharge plasma actuation on supersonic compressor cascade flow," Journal of Thermal Science, vol. 29, 2020.

[26] N.J. Webb, "Control of supersonic mixed-compression inlets using localized arc filament plasma actuators," 2010, February 2021, http://rave.ohiolink.edu/etdc/view?acc_num=osu1274714729.

[27] F. Falempin, A. A. Firsov, D. A. Yarantsev, M. A. Goldfeld, K. Timofeev, and S. B. Leonov, "Plasma control of shock wave configuration in off-design mode of $\mathrm{M}=2$ inlet," Experiments in Fluids, vol. 56, no. 3, p. 54, 2015.

[28] S. Leonov, C. Carter, A. Houpt, and T. Ombrello, "Mitigation of reflected shock wave by streamwise plasma array," in 7 th European Conference for Aeronautics and Space Sciences (EUCASS), vol. 24, pp. 1-11, Milan, Italy, 2017.

[29] W. A. Hongyu, L. I. Jun, J. I. Di, D. A. Hui, G. A. Tian, and W. U. Yun, "Effect of a transverse plasma jet on a shock wave induced by a ramp," Chinese journal of Aeronautics, vol. 30, no. 6, pp. 1854-1865, 2017.

[30] M. Tang, Y. Wu, S. Guo, Z. Sun, and Z. Luo, "Effect of the streamwise pulsed arc discharge array on shock wave/boundary layer interaction control," Physics of Fluids, vol. 32, no. 7, p. 076104, 2020.

[31] K. Kinefuchi, A. Y. Starikovskiy, and R. B. Miles, "Control of shock-wave/boundary-layer interaction using nanosecondpulsed plasma actuators," Journal of Propulsion and Power, vol. 34, pp. 909-919, 2018.

[32] S. Priebe and M. P. Martín, "Low-frequency unsteadiness in shock wave-turbulent boundary layer interaction," Journal of Fluid Mechanics, vol. 699, pp. 1-49, 2012.

[33] M. Wu and M. P. Martín, "Analysis of shock motion in shockwave and turbulent boundary layer interaction using direct numerical simulation data," Journal of Fluid Mechanics, vol. 594, pp. 71-83, 2008.

[34] L. J. Souverein, P. Dupont, J. F. Debiève, J. P. Dussauge, B. W. Van Oudheusden, and F. Scarano, "Effect of interaction strength on unsteadiness in shock-wave-induced separations," AIAA Journal, vol. 48, no. 7, pp. 1480-1493, 2010. 